\title{
A Rank-Order Procedure Applied to an Ethoexperimental Behavior Model—The Multivariate Concentric Square Field $^{\mathrm{TM}}$ (MCSF) Test
}

\author{
Bengt J. Meyerson ${ }^{1}$, Betty Jurek ${ }^{2}$, Erika Roman ${ }^{2 *}$ \\ ${ }^{1}$ Department of Neuroscience, Uppsala University, Uppsala, Sweden \\ ${ }^{2}$ Department of Pharmaceutical Biosciences, Uppsala University, Uppsala, Sweden \\ Email: *Erika.Roman@farmbio.uu.se
}

Received May 21, 2013; revised June 30, 2013; accepted July 25, 2013

Copyright (C) 2013 Bengt J. Meyerson et al. This is an open access article distributed under the Creative Commons Attribution License, which permits unrestricted use, distribution, and reproduction in any medium, provided the original work is properly cited.

\begin{abstract}
Designing relevant animal models in order to investigate the neurobiological basis for human mental disorders is an important challenge. The need for new tests to be developed and traditional tests to be improved has recently been emphasized. The authors propose a multivariate test approach, the multivariate concentric square field ${ }^{\mathrm{TM}}$ (MCSF) test. To measure and evaluate variation in the behavioral traits, we here put forward a statistical procedure of which the working title is "trend analysis". Low doses of the benzodiazepine agonist diazepam (DZP; 1.0, 1.5, or $2.0 \mathrm{mg} / \mathrm{kg}$ ) were used for exploring the use of the trend analysis in combination with multivariate data analysis for assessment of MCSF performance in rats. The commonly used elevated plus maze (EPM) test was used for comparison. The trend analysis comparing vehicle and the DZP1.5 groups revealed significantly higher general activity and risk-taking behavior in the DZP1.5 rats relative to vehicle rats. This finding was supported by multivariate data analysis procedures. It is concluded that the trend analysis together with multivariate data analysis procedures offers possibilities to extract information and illustrates effects obtained in the MCSF test. Diazepam in doses that have no apparent increase in open arm activity in the EPM was effective to alter the behavior in the MCSF test. The MCSF test and the use of multivariate data analysis and the proposed trend analysis may be useful alternatives to behavioral test batteries and traditionally used tests for the understanding of mechanisms underlying various mental states. Finally, the impact of an ethological reasoning and multivariate measures enabling behavioral profiling of animals may be a useful complementary methodology when phenotyping animals in behavioral neuroscience.
\end{abstract}

Keywords: Trend Analysis; Diazepam; Elevated Plus Maze; Multivariate Data Analysis

\section{Introduction}

Designing relevant animal models in order to investigate the neurobiological basis for human mental disorders is an important challenge. The difficulty is to find the animal performance that expresses and represents the particular human mental state that is the strategic aim of the investigation. The shortcoming of anthropocentrism in this is known and documented [1,2]. Many of the currently applied tests do not consider this problem. The clinical diagnosis, e.g. general anxiety disorder, may not contain elements that correspond to an animal's assessment of risk performed as visits to an open area of a field or elevated platform. Antianxiety drugs, e.g. ataractics, can alter such performance, however, argument by anal-

*Corresponding author. ogy is not always valid. The drug may influence two of each other independent central nervous domains.

The need for new tests to be developed and traditional tests to be improved has recently been emphasized [3-6]. Modifications of traditional tests have been proposed, which all provide a wider range of measures [7-9]. However, the focus of some of these new tests is still limited to specific predetermined mental states, e.g. anxiety-like behavior. The need for tests that deal with multiple measures, thus providing a behavioral profile rather than single parameters has been emphasized [10,11]. To this end, ethoexperimental composite tests have been designed [10-13]. We have proposed a multivariate test approach, which is unprejudiced in the sense that the animal is exposed to stimuli with different quality, it can choose between different environments designed to include oppor- 
tunity for exploration, risk assessment, risk taking, shelter seeking, and approach and avoidance in one and the same test session, i.e. the multivariate concentric square field $^{\mathrm{TM}}$ (MCSF) test. The guiding principle for the MCSF test is that test situation involves a free choice of different environmental settings and items that provide the opportunity to detect essential features of the animal's mentality. In this way a behavioral profile is generated $[11,14,15]$.

Tests like the MCSF imply that the animal has means to use a variety of behaviors that are triggered by the same executive mental process. To measure and evaluate variation in the behavioral traits, we here put forward a statistical procedure of which the working title is "trend analysis" [16]. Details and applications will be given in the following. Herein, low doses of the benzodiazepine agonist diazepam (DZP; 1.0, 1.5, or $2.0 \mathrm{mg} / \mathrm{kg}$ ) were used with the purpose of exploring the usefulness of the proposed trend analysis in combination with multivariate data analysis for assessment of MCSF performance in rats. The commonly used elevated plus maze (EPM) test was used for comparison with the MCSF.

\section{Materials and Methods}

\subsection{Animals and Housing}

Adult male Wistar rats (Sca:WI; Scanbur BK AB, Sollentuna, Sweden) were used. Upon arrival, the rats were housed 3 - 4 rats to a cage in transparent cages $(59 \times 38 \times$ $20 \mathrm{~cm}$ ) containing wood-chip bedding material and paper sheets for enrichment purpose. The cages were placed in temperature-controlled $\left(22^{\circ} \mathrm{C} \pm 0.5^{\circ} \mathrm{C}\right)$ and humiditycontrolled $(55 \% \pm 5 \%)$ cabinets with a reversed 12 -hour light/dark cycle, with lights off at 7:00 a.m. The rats were maintained on pellet food (R36 Labfor; Lactamin, Vadstena, Sweden) and water ad libitum. After arrival, the animals were left undisturbed and allowed to adapt to the reversed light/dark cycle for two weeks. All animal experiments were approved by the Uppsala Animal Ethical Committee and followed the guidelines of Swedish Legislation on Animal Experimentation (Animal Welfare Act SFS1998:56) and European Union Legislation (Directive 86/609/EEC).

\subsection{Drug}

Diazepam (Apoteket Production \& Laboratories; Apoteket AB, Stockholm, Sweden) was suspended in vehicle (45\% 2-hydroxypropyl-beta-cyclodextrin solution; SigmaAldrich Sweden AB, Stockholm, Sweden) and dispersed by ultrasound for $30 \mathrm{~min}$. This vehicle is reported benign with no adverse effects $[17,18]$.

\subsection{Experimental Procedure}

The MCSF was the main test. The EPM served as a basis for comparison to evaluate the doses since this is one of the most common tests used in this matter. The animals were tested in the EPM test one week after the MCSF trial. The rats were handled during the week prior to testing began. The handling procedure consisted of individual handling, weighing, and adaptation to the transportation bucket that was used to take the animals from the home cage to the test arenas. The animals were 11 weeks old and had a mean $( \pm$ S.E.M.) bodyweight of 453 $\pm 4 \mathrm{~g}$ when the behavioral testing started. Animals from the different treatment groups were alternated during the testing in order to avoid time and order bias. All testing was performed in a separate room with similar conditions of temperature and humidity as those in the animal room, and with a masking background noise. Observations were made during the dark period of the light/dark cycle.

\subsection{Drug Administration}

The rats were randomly assigned to experimental and control groups. Diazepam was injected intraperitoneally (i.p.) at a dose of $0.0 \mathrm{mg} / \mathrm{kg}$ (vehicle, $\mathrm{n}=8), 1.0 \mathrm{mg} / \mathrm{kg}(\mathrm{n}$ $=9), 1.5 \mathrm{mg} / \mathrm{kg}(\mathrm{n}=9)$ or $2.0 \mathrm{mg} / \mathrm{kg}(\mathrm{n}=9)$. To control for potential effects induced by the vehicle, a fifth group received $0.9 \% \mathrm{NaCl}(\mathrm{n}=8)$. All injections were given in a volume of $1 \mathrm{ml} / \mathrm{kg}$ and administered $30 \mathrm{~min}$ prior to testing. The animals were returned to their respective home cages after the injections.

\subsection{The MCSF Test}

The MCSF test has been described in detail elsewhere $[11,14,15]$. The MCSF arena consists of a square field $(100 \times 100 \mathrm{~cm})$ with a smaller square field $(70 \times 70 \mathrm{~cm})$ located in the center of the larger one (Figure 1). The walls are $25 \mathrm{~cm}$ high except for the walls surrounding the bridge, which are $40 \mathrm{~cm}$ high. A photocell device is located under the hole board floor of the hurdle, allowing recording of head dips into the holes. The entire arena is divided into zones, which forms the basis of the description and the variables of the animals' performance in this test.

The animal to be tested was released in the center facing the wall without openings (Figure 1). The test session lasted $20 \mathrm{~min}$. The approximate light conditions $(\mathrm{l} \times)$ in the MCSF arena were as follows: dark corner room (DCR): $<1$; center, corridors and hurdle: $10-15$; slope: 50; and bridge: $600-650$. After each test, the arena was wiped with a cloth containing $10 \%$ ethanol solution and sufficient time was allowed for the floor and walls to dry before the next animal was placed in the arena.

The following calculations were made: sum of visits to the corridors (FRQ TOTCORR), sum of visits to all zones (TOTACT) and total time spent in the corridors (DUR TOTCORR). 


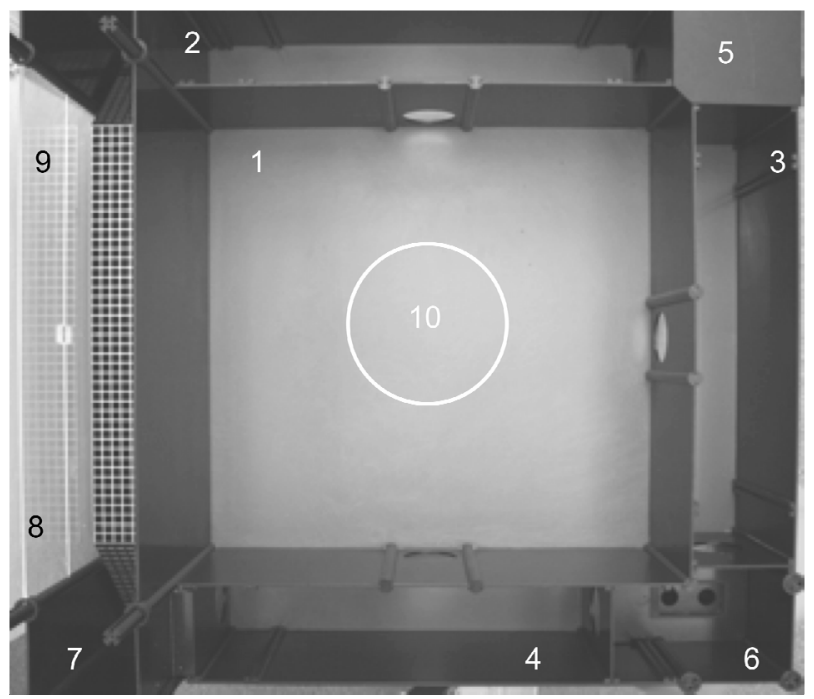

Figure 1. The MCSF arena $(100 \times 100 \mathrm{~cm})$ and the defined zones numbered as follows: (1) Center, the center field of the arena; (2-4) Corridors, the corridors surrounding the center field; (5) Dark corner room (DCR), a shaded room considered to be a safe area; (6) Hurdle with photocell, a high passage to a hole board introduced to test the motor ability of the animal and the exploratory drive of nose poking into the hole board; (7) Slope, considered to be an area where the animal has to assess the risk of visiting the bridge; (8) Bridge entrance, considered to be an area where the animal has to assess the risk of visiting the bridge; (9) Bridge, an elevated and illuminated bridge construction considered to be an area associated with risk; (10) Central circle, a circular zone in the middle of the center field considered to be an area associated with risk.

\subsection{The EPM Test}

The EPM consists of four arms, each $40 \mathrm{~cm}$ long and 10 $\mathrm{cm}$ wide, arranged in the shape of a plus sign and elevated $51 \mathrm{~cm}$ from the floor. Two opposite arms are open, whereas the other two are closed with 40-cm-high walls but end of arms open. The area inside the center of the EPM $(10 \times 10 \mathrm{~cm})$ is not considered to be either an open or closed arm. The rat to be tested was placed in the center of the EPM, facing an open arm. Each rat was tested for $10 \mathrm{~min}$. After each rat, the EPM was wiped clean with $10 \%$ ethanol solution and sufficient time was allowed for the apparatus to dry before the next animal was placed in the maze. The approximate light conditions $(1 \times)$ in the EPM were as follows: open arms: 10; closed arms: 2. The total number of crossings to the different zones was used as a measure of locomotor activity.

\subsection{Behavioral Recordings}

The animals were observed from an adjacent room. Recordings of stretched attend postures (SAPs), rearing and grooming were done by direct observation. The number of fecal boli and urinations were counted after each ses- sion. Manual scoring of the behavior was performed using the software Score 3.3 (Soldis, Uppsala, Sweden). Visits to the defined zones were only scored as such if both hind legs had crossed over into that section. The latency (LAT, s) of first visiting a zone, frequency (FRQ) of visits, and duration (DUR, $s$ ) of time spent in a certain zone, and also the number of animals visiting each zone (OCCURRENCE) were all registered. The mean duration per visit (DUR/FRQ, s), the percentage duration and percentage number of visits to all zones were calculated. Ethovision 2.3 (Noldus Information Technology, Wageningen, The Netherlands) was used for recording of distance $(\mathrm{cm})$ and velocity $(\mathrm{cm} / \mathrm{s})$ in the MCSF arena.

\subsection{Statistical Analyses}

\subsubsection{Analysis of MCSF and EPM Parameters}

The parameters were not normally distributed according to the Shapiro-Wilk's W test and therefore nonparametric statistics were used. The Kruskal-Wallis test was used for overall comparisons between the groups. When a significant difference was found, further group wise analyses were performed using the Mann-Whitney U-test, which also was used for all group wise comparisons. Differences were considered statistically significant at $\mathrm{p} \leq 0.05$. Statistica 10.0 (StatSoft Inc., Tulsa, OK) was used for the statistical analyses.

\subsubsection{Multivariate Data Analysis of MCSF Parameters}

In addition to traditional statistical analysis, the multivariate methods principal component analysis (PCA) and partial least square discriminant analysis (PLS-DA) were used. PLS-DA is a regression extension of PCA and calculates the relationship between a Y-matrix (here experimental groups) and an X-matrix (here MCSF parameters). The weights for the $\mathrm{X}$-variables (in the analysis denoted w) indicate the importance of these variables, while the weights for the $\mathrm{Y}$-variables (in the analysis denoted c) indicate which Y-variables are modeled in the respective PLS model dimensions. When these coefficients are plotted in a $\mathrm{w}^{*} \mathrm{c}$ plot, a picture showing the relationships between $\mathrm{X}$ and $\mathrm{Y}$ is obtained [19]. The SIMCA-P+ software version 12.0 (Umetrics AB, Umeå, Sweden) was used.

\subsubsection{The Trend Analysis}

The trend analysis is based on the fact that the individual may choose different behavior strategies within the same or similar functional context, emanating from the same mental state. The behavioral parameters may to some extent have different magnitudes. The rank-order procedure disregards any such quantitative differences. For each parameter, the animals are ranked against each other so that the rat with the lowest score is given the lowest rank 
and the animal with the highest score is given the highest rank value. Thus, the comparisons are based on the relative position of the animal within the population tested. Note that the comparison may comprise all or selected treatment categories (see figure legends). The breaking down of the data in this way rests on the assumption that if a particular experimental procedure influences the behavior in a way that relates to the animals' personality traits, then the rank order mentioned previously might become altered. If so, the personality trait is an important factor that should be considered in the evaluation of the results [16].

The trend analysis requires that the animal has a number of alternative behavioral possibilities to express a certain mental condition e.g. various areas for risk assessment or risk taking. This is provided in a multivariate test such as the MCSF but not in the EPM.

\section{Results}

\subsection{The MCSF Test}

The descriptive results from the MCSF test in which the groups, saline, vehicle, DZP at $1.0 \mathrm{mg} / \mathrm{kg}$ (DZP1.0), 1.5 $\mathrm{mg} / \mathrm{kg}$ (DZP1.5), and $2.0 \mathrm{mg} / \mathrm{kg}$ (DZP2.0), were compared are given in Table 1. Significant differences were mainly found for parameters of relevance for general activity (total activity, visits to the corridors, duration per visit to the center and velocity in the arena). Some differences were found for parameters of relevance to exploratory activity (duration per visit in the corridors and in the hurdle) and risk-taking behavior (number of visits to the central circle and distance and velocity in the central circle).

The PLS-DA analysis in which all MCSF parameters were included is shown in Figure 2. The DZP1.5 group

Table 1. Results from the multivariate concentric square field ${ }^{\mathrm{TM}}$ (MCSF) test in male Wistar rats treated with saline, vehicle, diazepam $1.0 \mathrm{mg} / \mathrm{kg}$ (DZP1.0), diazepam $1.5 \mathrm{mg} / \mathrm{kg}$ (DZP1.5) or diazepam $2.0 \mathrm{mg} / \mathrm{kg}$ (DZP2.0) $30 \mathrm{~min}$ prior to assessment.

\begin{tabular}{|c|c|c|c|c|c|c|c|c|c|c|c|}
\hline $\begin{array}{l}\text { Functional } \\
\text { categories }\end{array}$ & Saline & & Vehicle & & DZP 1.0 & & DZP 1.5 & & DZP 2.0 & & $\mathbf{K}-\mathbf{W}$ \\
\hline Parameters & Median & QR & Median & QR & Median & QR & Median & QR & Median & QR & \\
\hline \multicolumn{12}{|l|}{ General Activity } \\
\hline TOTACT & 63.5 & 18.0 & 61.5 & 18.5 & 69.0 & 16.0 & $96.0^{\text {all }}$ & 20.0 & 54.5 & 52.5 & $\mathrm{H}=14.95, \mathrm{p}<0.05$ \\
\hline FRQ TOTCORR & 19.0 & 8.0 & 20.0 & 5.0 & 20.5 & 11.0 & $30.0^{\text {all }}$ & 6.0 & 17.0 & 17.0 & $\mathrm{H}=14.20, \mathrm{p}<0.01$ \\
\hline FRQ center & 6.0 & 10.0 & 7.5 & 6.5 & 7.0 & 3.0 & $17.0^{\text {all }}$ & 4.0 & 6.5 & 10.5 & $\mathrm{H}=12.43, \mathrm{p}<0.05$ \\
\hline DUR center & 116.0 & 116.1 & 151.4 & 159.6 & 146.6 & 99.4 & 152.7 & 116.3 & 178.2 & 170.2 & n.s. \\
\hline DUR/FRQ center & 18.7 & 9.6 & 17.9 & 11.2 & 15.7 & 9.2 & $10.1^{\mathrm{a}, \mathrm{b}, \mathrm{e}}$ & 6.3 & 21.0 & 11.4 & $\mathrm{H}=13.39, \mathrm{p}<0.01$ \\
\hline Distance arena & 3870.5 & 2812.8 & 4265.7 & 961.2 & 4328.2 & 1041.1 & 6080.4 & 821.3 & 3959.0 & 3690.2 & n.s. \\
\hline Velocity arena & 3.9 & 2.2 & 3.8 & 1.0 & 3.7 & 0.7 & $5.4^{\mathrm{a}, \mathrm{b}, \mathrm{c}}$ & 0.9 & 3.6 & 2.1 & $\mathrm{H}=9.55, \mathrm{p}<0.05$ \\
\hline \multicolumn{12}{|l|}{$\begin{array}{c}\text { Exploratory } \\
\text { activity }\end{array}$} \\
\hline LAT leave center & 49.4 & 63.2 & 53.2 & 25.5 & 61.5 & 56.1 & 38.3 & 24.6 & 79.1 & 103.8 & n.s. \\
\hline DUR TOTCORR & 437.8 & 112.9 & 440.4 & 71.2 & 352.9 & 157.6 & 398.8 & 58.8 & 304.3 & 214.5 & n.s. \\
\hline DUR/FRQ TOTCORR & 23.8 & 19.0 & 20.3 & 5.9 & $16.7^{\mathrm{a}}$ & 4.0 & $13.3^{\mathrm{a}, \mathrm{b}}$ & 1.6 & $17.1^{\mathrm{a}}$ & 4.0 & $\mathrm{H}=14.19, \mathrm{p}<0.01$ \\
\hline LAT hurdle & 191.3 & 189.9 & 185.8 & 253.8 & 126.8 & 234.8 & 171.3 & 127.2 & 196.0 & 174.9 & n.s. \\
\hline OCC LAT hurdle & $8 / 8$ & & $7 / 8$ & & $9 / 10$ & & $9 / 9$ & & $5 / 8$ & & - \\
\hline FRQ hurdle & 4.5 & 4.0 & 7.0 & 4.0 & 8.5 & 4.0 & 8.0 & 3.0 & 4.5 & 9.0 & n.s. \\
\hline DUR hurdle & 78.9 & 63.6 & 123.0 & 95.1 & 96.8 & 21.4 & 107.3 & 53.1 & 32.2 & 119.8 & n.s. \\
\hline DUR/FRQ hurdle & 15.6 & 10.2 & 14.4 & 7.4 & 12.4 & 7.9 & 13.3 & 3.2 & $7.0^{\mathrm{a}, \mathrm{b}, \mathrm{d}}$ & 11.0 & $\mathrm{H}=9.88, \mathrm{p}<0.05$ \\
\hline Photocell counts & 4.5 & 8.0 & 7.0 & 6.0 & 7.0 & 7.0 & 9.0 & 6.0 & 5.0 & 9.0 & n.s. \\
\hline Rearing & 73.0 & 38.0 & 73.5 & 28.0 & 60.5 & 37.0 & 61.0 & 23.0 & 39.0 & 54.5 & n.s. \\
\hline \multicolumn{12}{|l|}{ Risk assessment } \\
\hline LAT slope & 141.5 & 246.4 & 239.0 & 249.0 & 102.0 & 55.0 & 123.1 & 169.6 & 156.8 & 191.5 & n.s. \\
\hline OCC LAT slope & $8 / 8$ & & $7 / 8$ & & $9 / 10$ & & $9 / 9$ & & $6 / 8$ & & - \\
\hline FRQ slope & 10.0 & 4.0 & 8.5 & 5.5 & 12.5 & 5.0 & 13.0 & 3.0 & 7.0 & 10.5 & n.s. \\
\hline DUR slope & 173.9 & 132.4 & 95.3 & 80.4 & 182.9 & 156.2 & 110.2 & 28.8 & 67.1 & 242.0 & n.s. \\
\hline DUR/FRQ slope & 14.7 & 19.0 & 9.1 & 7.7 & 15.0 & 14.0 & 10.2 & 0.9 & 4.6 & 19.6 & n.s. \\
\hline LAT bridge entrance & 152.9 & 246.8 & 243.5 & 250.6 & 125.7 & 51.7 & 129.6 & 168.5 & 162.7 & 184.0 & n.s. \\
\hline OCC LAT bridge entrance & $8 / 8$ & & $7 / 8$ & & $9 / 10$ & & $9 / 9$ & & $6 / 8$ & & - \\
\hline FRQ bridge entrance & 8.0 & 4.5 & 7.5 & 7.5 & 12.0 & 6.0 & 13.0 & 4.0 & 6.5 & 9.5 & n.s. \\
\hline DUR bridge entrance & 125.4 & 65.9 & 91.0 & 58.9 & 125.7 & 85.6 & 101.5 & 53.1 & 47.9 & 96.9 & n.s. \\
\hline DUR/FRQ bridge entrance & 12.9 & 10.0 & 9.3 & 5.3 & 10.3 & 7.4 & 9.5 & 4.0 & 7.5 & 7.7 & n.s. \\
\hline
\end{tabular}




\section{Continued}

\begin{tabular}{|c|c|c|c|c|c|c|c|c|c|c|c|}
\hline Risk taking & & & & & & & & & & & \\
\hline LAT bridge & 194.8 & 284.3 & 360.7 & 281.2 & 132.0 & 31.9 & 184.7 & 122.5 & 219.6 & 179.7 & n.s. \\
\hline OCC LAT bridge & $7 / 8$ & & $7 / 8$ & & $9 / 10$ & & $9 / 9$ & & $6 / 8$ & & - \\
\hline FRQ bridge & 2.0 & 2.0 & 3.0 & 3.5 & 4.5 & 4.0 & 5.0 & 3.0 & 2.5 & 3.5 & n.s. \\
\hline DUR bridge & 101.1 & 70.6 & 98.4 & 160.1 & 154.2 & 136.1 & 119.3 & 97.8 & 82.1 & 138.3 & n.s. \\
\hline DUR/FRQ bridge & 37.6 & 14.8 & 27.2 & 19.1 & 31.6 & 14.4 & 27.2 & 9.8 & 23.9 & 17.7 & n.s. \\
\hline LAT CTRCI & 43.0 & 13.1 & 9.2 & 589.8 & 20.3 & 148.2 & 52.8 & 104.3 & 35.1 & 272.6 & n.s. \\
\hline OCC LAT CTRCI & $5 / 8$ & & $5 / 8$ & & $9 / 10$ & & $9 / 9$ & & $7 / 8$ & & - \\
\hline FRQ CTRCI & 2.0 & 4.0 & 2.0 & 3.0 & 2.0 & 2.0 & $6.0^{\text {all }}$ & 2.0 & 2.0 & 4.0 & $H=13.15, p=0.01$ \\
\hline DUR CTRCI & 2.8 & 12.0 & 7.6 & 8.6 & 3.8 & 5.5 & 10.3 & 3.7 & 5.7 & 7.1 & n.s. \\
\hline DUR/FRQ CTRCI & 1.4 & 2.4 & 2.2 & 3.5 & 1.9 & 0.8 & 1.6 & 0.8 & 1.4 & 0.8 & n.s. \\
\hline DISTANCE CTRCI & 51.1 & 131.8 & 67.7 & 104.4 & 64.9 & 49.4 & $193.6^{\text {all }}$ & 45.3 & 63.2 & 102.7 & $\mathrm{H}=14.54, \mathrm{p}<0.01$ \\
\hline VELOCITY CTRCI & 8.1 & 10.6 & 5.7 & 8.0 & $12.2^{\mathrm{b}}$ & 5.8 & $15.1^{\mathrm{a}, \mathrm{b}}$ & 5.0 & $16.9^{\mathrm{b}}$ & 17.5 & $\mathrm{H}=16.31, \mathrm{p}<0.01$ \\
\hline \multicolumn{12}{|l|}{ Shelter seeking } \\
\hline LAT DCR & 132.6 & 369.6 & 109.1 & 619.8 & 534.1 & 276.9 & 312.5 & 362.9 & 331.9 & 883.5 & n.s. \\
\hline OCC LAT DCR & $5 / 8$ & & $7 / 8$ & & $9 / 10$ & & $9 / 9$ & & $7 / 8$ & & - \\
\hline FRQ DCR & 2.5 & 4.5 & 4.5 & 8.5 & 2.5 & 1.0 & 6.0 & 4.0 & 2.5 & 6.0 & n.s. \\
\hline DUR DCR & 61.6 & 108.5 & 121.1 & 223.1 & 71.6 & 69.1 & 101.7 & 150.9 & 42.7 & 662.1 & n.s. \\
\hline DUR/FRQ DCR & 20.0 & 22.9 & 32.0 & 28.0 & 19.2 & 36.3 & 19.5 & 14.2 & 21.3 & 71.7 & n.s. \\
\hline \multicolumn{12}{|l|}{ Other } \\
\hline Grooming & 0.5 & 1.5 & 0.0 & 1.0 & 1.5 & 2.0 & 1.0 & 1.0 & 0.0 & 1.0 & n.s. \\
\hline Fecal boli & 0.0 & 0.0 & 0.0 & 3.5 & 0.0 & 3.0 & 0.0 & 0.0 & 0.0 & 1.0 & n.s. \\
\hline Urinations & 0.8 & 1.0 & 2.5 & 2.5 & 1.5 & 3.0 & 3.0 & 3.0 & 1.0 & 1.5 & n.s. \\
\hline \multicolumn{12}{|l|}{$\begin{array}{c}\text { Anxiety-like } \\
\text { behavior }\end{array}$} \\
\hline FRQ risk/shelter index & 0.0 & 1.4 & -0.3 & 1.0 & 0.1 & 0.7 & -0.1 & 0.5 & 0.2 & 1.3 & n.s. \\
\hline DUR risk/shelter index & 0.3 & 1.1 & 0.0 & 1.3 & 0.3 & 0.7 & 0.1 & 0.7 & 0.5 & 1.6 & n.s. \\
\hline \multicolumn{12}{|l|}{$\begin{array}{c}\text { Impulsive-like } \\
\text { behavior }\end{array}$} \\
\hline Slope/bridge interval & -0.2 & 1.7 & -0.1 & 0.3 & -0.1 & 0.5 & -0.3 & 0.8 & -0.4 & 0.6 & n.s. \\
\hline
\end{tabular}

Behavioral parameters recorded during the 20-min trial of the MCSF test. Occurrence (OCC) is shown for the latency measure for the zones that were not visited by all animals in each group; latencies were treated as missing values if the zones were not visited. No significant difference in occurrence was revealed (Chi-square test). Values represent median and quartile range (QR). ${ }^{\text {all }}$ Significantly different from all other groups; ${ }^{\mathrm{a}}$ Significantly different from the saline group; ${ }^{\mathrm{b}}$ Significantly different from the vehicle group; ${ }^{\mathrm{c}}$ Significantly different from the DZP1.0 group; ${ }^{\mathrm{d}}$ Significantly different from the DZP1.5 group; ${ }^{\mathrm{e}}$ Significantly different from the DZP2.0 group ( $\mathrm{p} \leq 0.05$; Mann-Whitney U-test). Abbreviations: CTRCI, central circle; DCR, dark corner room; DUR, duration (s); DUR/ FRQ, duration per visit (s); FRQ, frequency; K-W, Kruskal-Wallis test; LAT, latency (s); OCC, occurrence; TOTACT, total activity, i.e. the sum of all frequencies; TOTCORR; total corridor, i.e. the sum of all corridors.

is located in the upper left quadrant separated from the other groups. Parameters of relevance for this loading are mainly related to general activity (e.g. total activity, distance and velocity measures, and performance in the corridors), exploration (e.g. performance in the corridors and hurdle, and photocell counts) and risk-taking behavior (performance in the central circle).

The basis for the grouping of parameters into the functional categories in the trend analysis is shown in Figure 3. Using a PCA, the loading of the descriptive parameters included in the trend analysis is shown in the loading plot. Here, parameters contributing similar information are grouped together and are thus correlated. When parameters are positioned on opposite sides of the plot, in diagonally opposed quadrants they are inversely correlated [19]. The strongest correlations are found for parameters included in the functional categories general activity, exploration and shelter seeking.

In the trend analysis, the rank values for each parame- ter are summed into a sum rank for each functional category (i.e. general activity, exploration, risk assessment, risk taking and shelter seeking). The results from the trend analysis in which the relative position of the animal within the population tested is shown in Figure 4. The Kruskal-Wallis test revealed a significant difference for the category general activity $(\mathrm{H}=14.18, \mathrm{p}<0.01)$, with the DZP1.5 rats displaying the highest activity, and a borderline effect in risk assessment $(\mathrm{H}=8.35, \mathrm{p}<0.08)$. Moreover, when performing a PCA on the sum rank scores from the trend analysis (Figure 5), the DZP1.5 rats were mainly located in the upper right quadrant with general activity and risk taking as loading parameters.

Based on these findings, further pair-wise rankings were performed comparing saline versus vehicle (no significant differences), saline versus DZP1.5, and vehicle versus DZP1.5. The trend analysis comparing saline and the DZP1.5 groups revealed significantly higher general activity in the DZP1.5 rats relative to saline rats $(Z=$ 


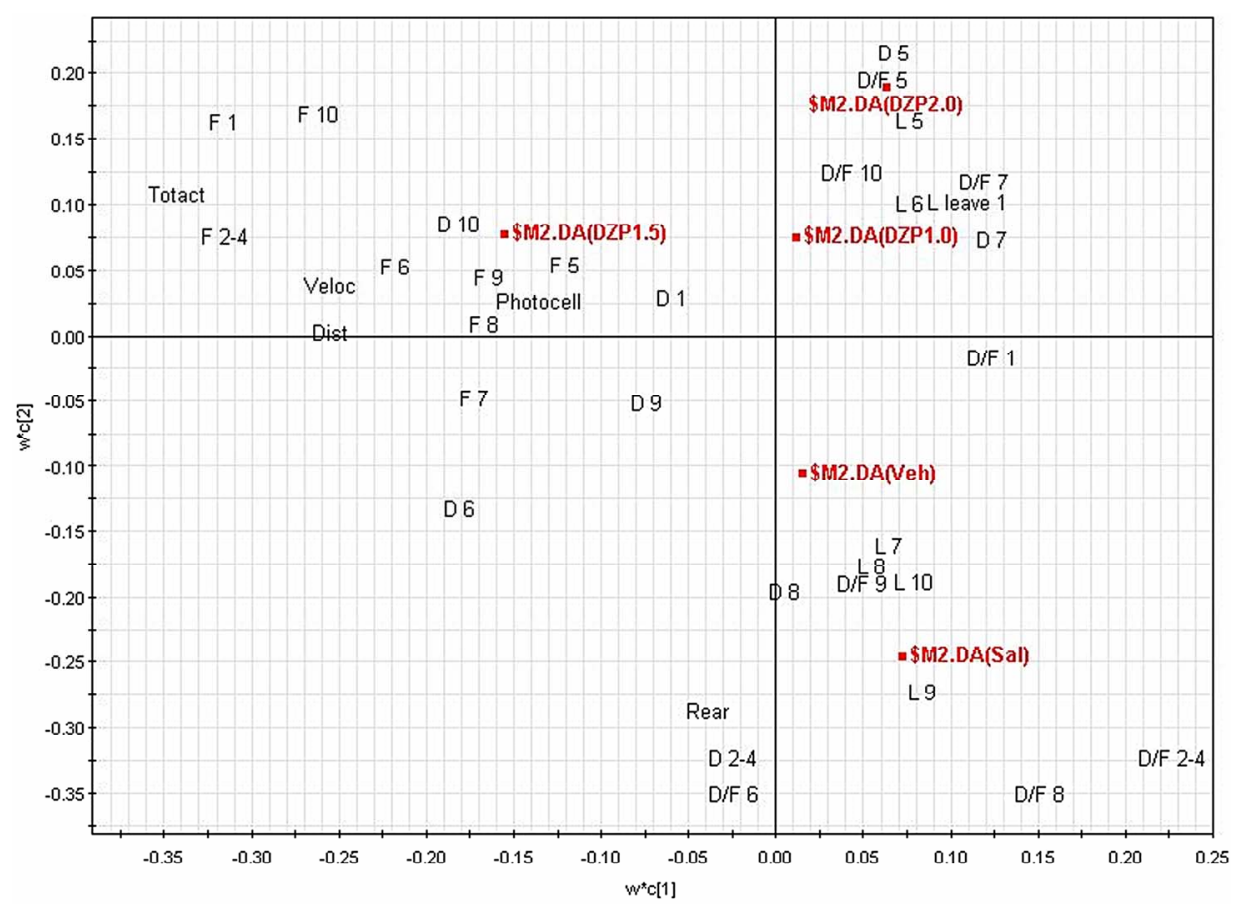

Abbreviations: D: duration (s); D/F: duration per visit (s); Dist: distance (cm); F: frequency; L: latency (s); Photocell: number of head dips; Rear: number of rearings; Totact: total activity, i.e. sum of all frequencies; Veloc: velocity $(\mathrm{cm} / \mathrm{s})$. The numbers correspond to the following zones: 1: center; 2-4: corridors; 5: dark corner room (DCR); 6 : hurdle; 7: slope; 8: bridge entrance; 9: bridge; 10: central circle.

Figure 2. Multivariate partial least square discriminant analysis (PLS-DA) of MCSF performance. PLS-DA scatter plot of MCSF parameters of relevance to the experimental groups saline (sal), vehicle (veh), DZP at $1.0 \mathrm{mg} / \mathrm{kg}(\mathrm{DZP1.0}), 1.5 \mathrm{mg} / \mathrm{kg}$ (DZP1.5), and $2.0 \mathrm{mg} / \mathrm{kg}(\mathrm{DZP} 2.0) . \mathrm{R}^{2} \mathrm{X}(\mathrm{cum})=0.419, \mathrm{R}^{2} Y(\mathrm{cum})=0.162, \mathrm{Q}^{2}$ (cum) $=-0.063$, two components.

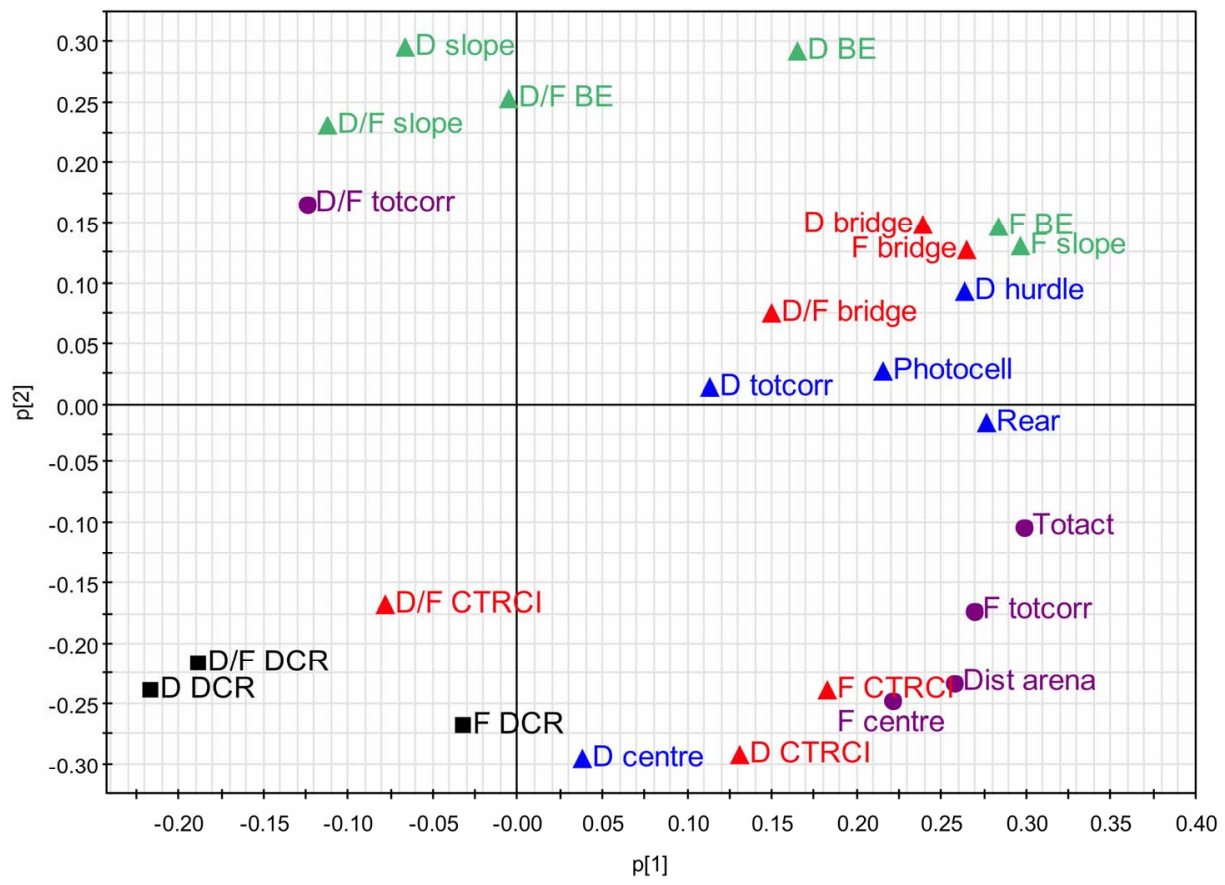

Abbreviations: BE, bridge entrance; CTRCI, central circle; D, duration; DCR, dark corner room; D/F, duration per visit; Dist, distance; F, frequency, totcorr; total corridors, i.e. sum of all corridors.

Figure 3. Principal component analysis (PCA) loading plot showing the MCSF parameters included in the functional category general activity (violet dots), exploration (blue triangles), risk assessment (green triangles), risk taking (red triangles) and shelter seeking (black boxes) in the trend analysis. $R^{2} X($ cum $)=0.569, Q^{2}(\mathrm{cum})=0.313$, two components. 


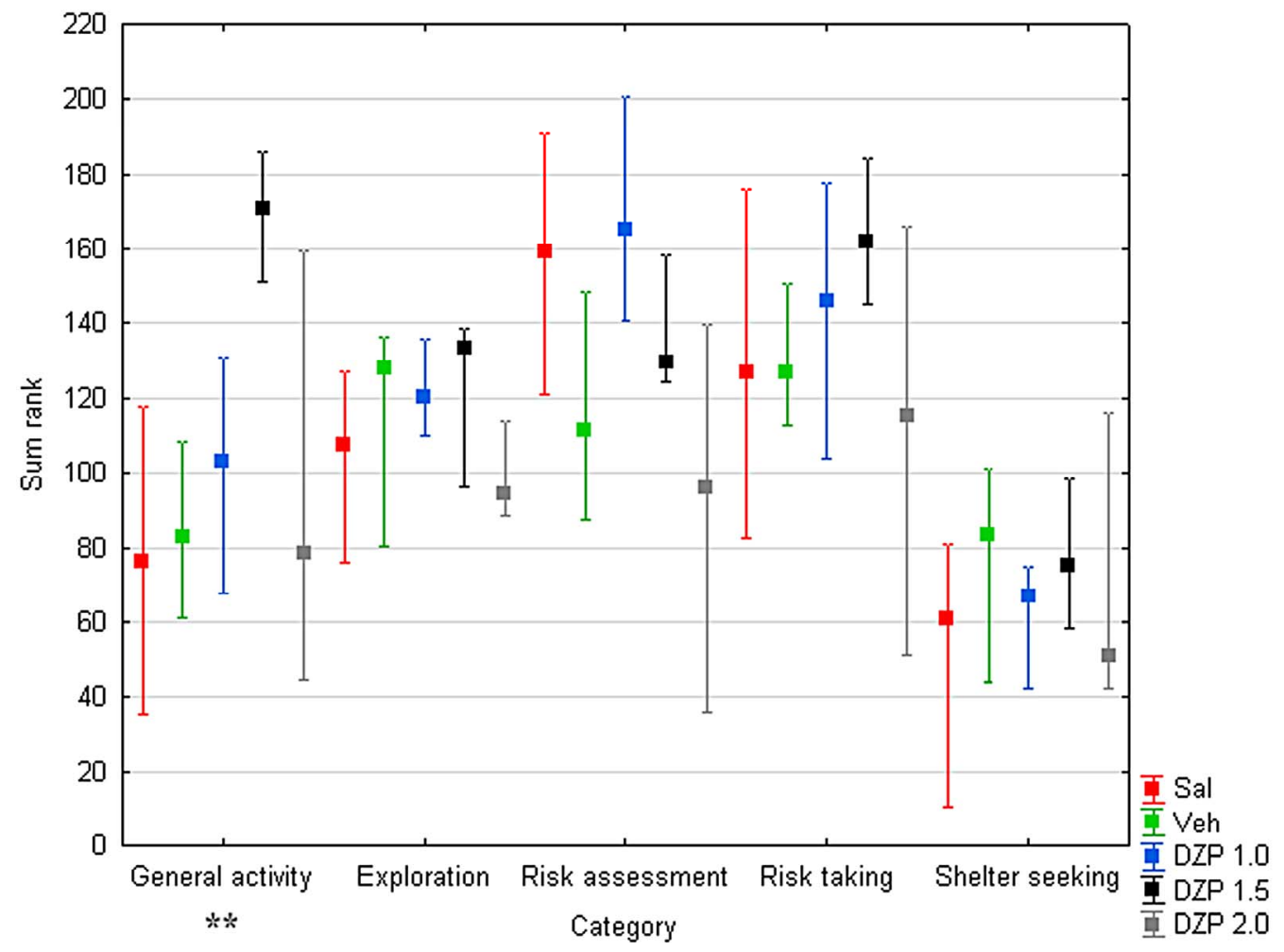

Figure 4. The MCSF trend analysis with the relative position of the animals within the entire population. Individual rank values for parameters included in the functional categories are summed. Values represent median and quartile range. An overall difference was found for the category general activity $\left({ }^{* *} \mathrm{p}<0.01\right.$, Kruskal-Wallis test).

$-3.32, \mathrm{p}<0.001)$. The trend analysis comparing vehicle and DZP1.5 groups revealed significantly higher general activity and risk-taking behavior, respecively, in DZP1.5 rats relative to vehicle rats (Figure 6).

\subsection{The EPM Test}

An analysis covering the parameters usually made use of for calculating the results of the EPM test revealed merely a significant effect of the treatment in number of rearing actions (Table 2).

\section{Discussion}

The aim of the present study was to demonstrate a multivariate approach to analyze the behavioral result of a drug treatment expected to alter a mental state. Diazepam is for clinical use classified as a tranquilizer, that is, the drug has ataractic effects.

This proposal should be looked upon as an alternative methods that starts out from models based on an anthropocentric paradigm generated from human personality disorders rather than considering the impact of an ethological reasoning. To acquire information on the effects of a stimulus on behavior traits, it is here suggested to use an ethoexperimental approach and utilize a construction that permits a multivariate test situation and concomitant suitable statistical processing (non-parametric methods, PCA, PLS-DA, trend analysis).

The MCSF is launched as a complementary methodological possibility to understand mechanisms underlying various mental states. In a multivariate test situation, several measures can be taken; these can provide a profile rather than focusing on any particular behavior. Inherent in the MCSF procedure is the freedom of choice regarding staying in areas with different magnitude of risk versus sheltered areas $[11,14,15]$. The various areas have been worked out to be incentives for exploratory activity, and approach or avoidance responses in expected reward and risk situations [11]. The MCSF test has been evaluated with regard to areas associated with risk and safety. Lactating female rats retrieved their pups from the open and brightly illuminated bridge area into the sheltered DCR area, and food-deprived male rats carried food pellets from the bridge and hoarded them in the DCR [11]. During the trial time of $20 \mathrm{~min}$, the animal acquires experience of the experimental set-up that is manifested in the performance when repeatedly tested 40 - 50 days after the first trial $[11,20]$. In addition, exposure to a presumed aversive air-puff resulted in longer latency in first visiting and fewer animals visiting the area associated with the air-puff when tested two weeks later [21].

When working with large data sets containing highly 


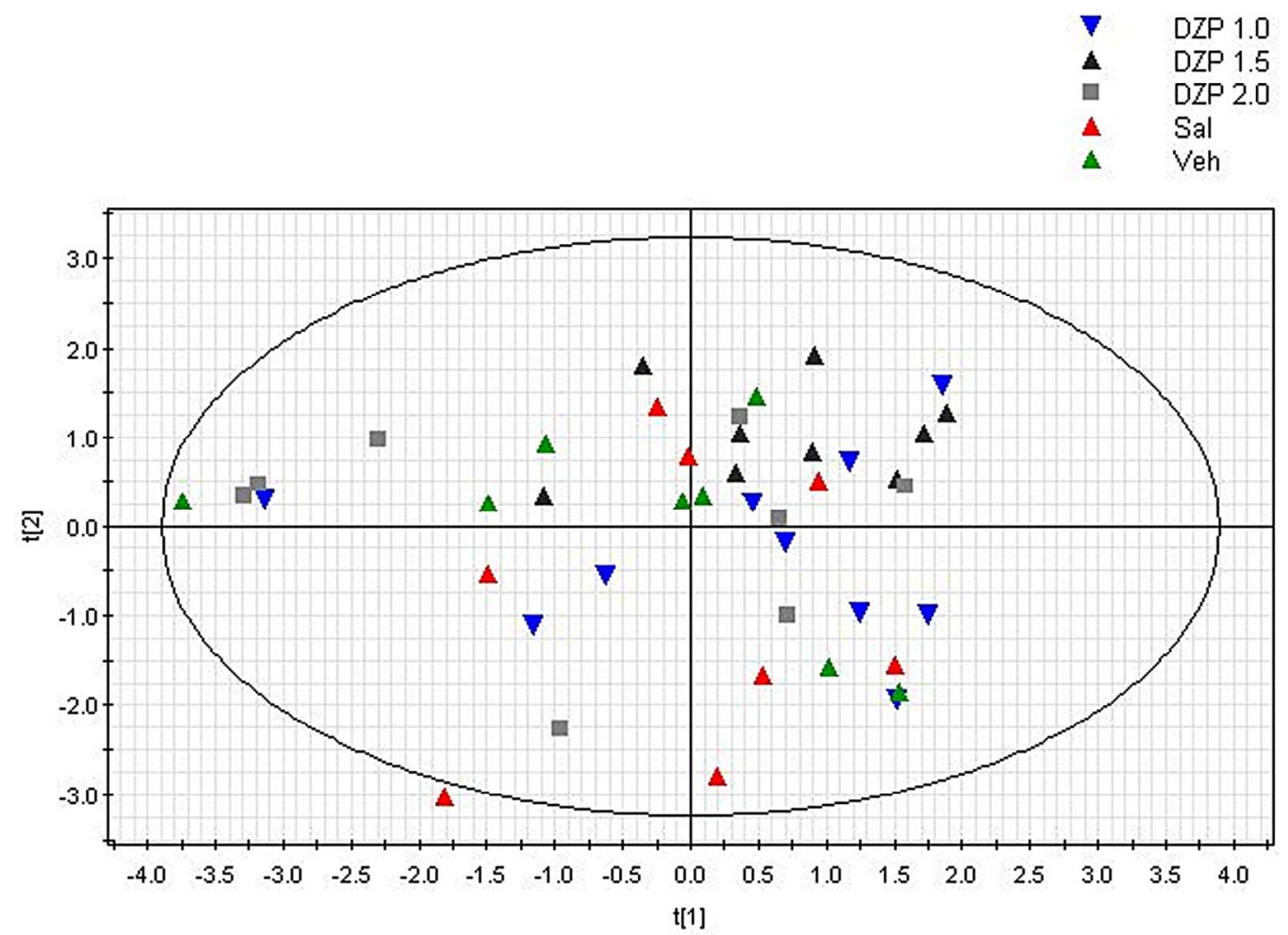

(a)

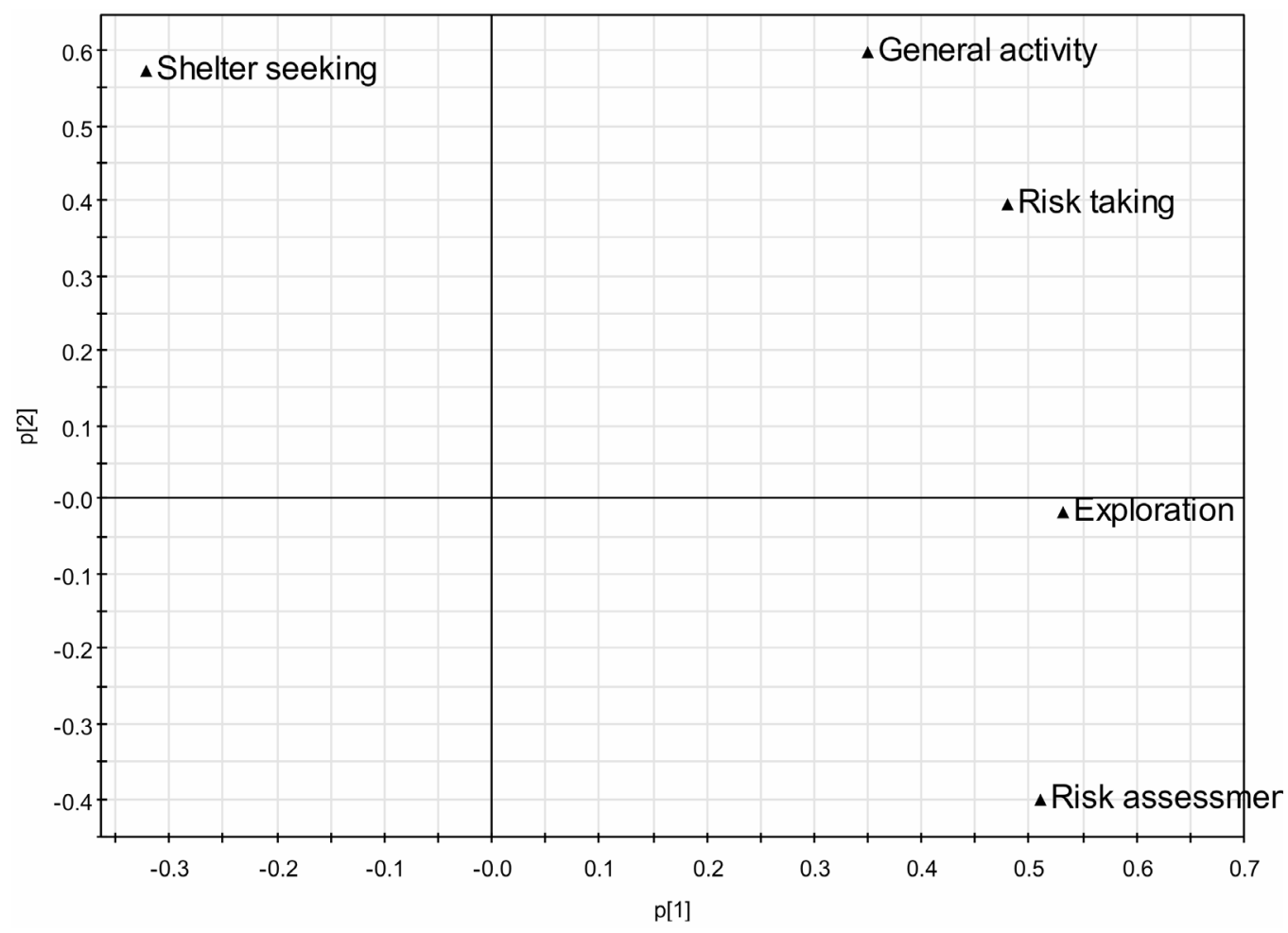

(b)

Figure 5. Principal component analysis (PCA) on the sum rank scores from the trend analysis based on the relative position of the animals within the entire population. (a) The score plot showing the individuals in the groups saline (sal), vehicle (veh), DZP at $1.0 \mathrm{mg} / \mathrm{kg}$ (DZP1.0), $1.5 \mathrm{mg} / \mathrm{kg}$ (DZP1.5), and $2.0 \mathrm{mg} / \mathrm{kg}$ (DZP2.0), and specifically the grouping of the DZP1.5 rats in the upper right quadrant; (b) The loading plot showing the functional category parameters included in the trend analysis. $R^{2} X($ cum $)=0.776, Q^{2}($ cum $)=0.285$, two components. 


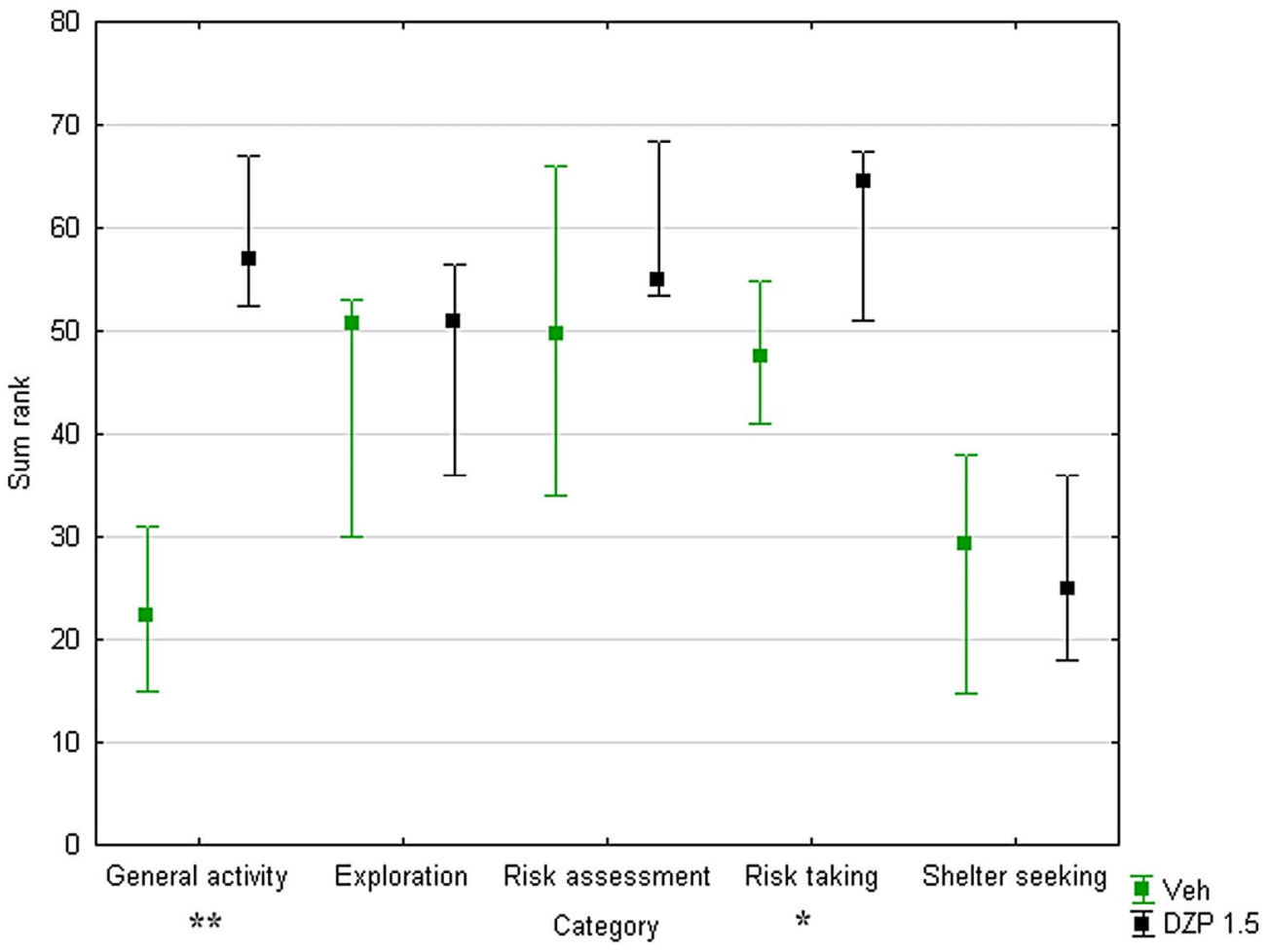

Figure 6. The MCSF trend analysis with the relative position of the animals within the vehicle and DZP1.5 groups. Individual rank values for parameters included in the functional categories are summed. Values represent median and quartile range. * $p$ $<0.05,{ }^{* * *} \mathrm{p}<0.01$ comparing vehicle and DZP1.5 groups (Mann-Whitney U-test).

Table 2. Results from the elevated plus maze (EPM) test in male Wistar rats treated with saline, vehicle, $\mathrm{diazepam} 1.0 \mathrm{mg} / \mathrm{kg}$ (DZP1.0), diazepam $1.5 \mathrm{mg} / \mathrm{kg}$ (DZP1.5) or diazepam $2.0 \mathrm{mg} / \mathrm{kg}$ (DZP2.0) $30 \mathrm{~min}$ prior to assessment.

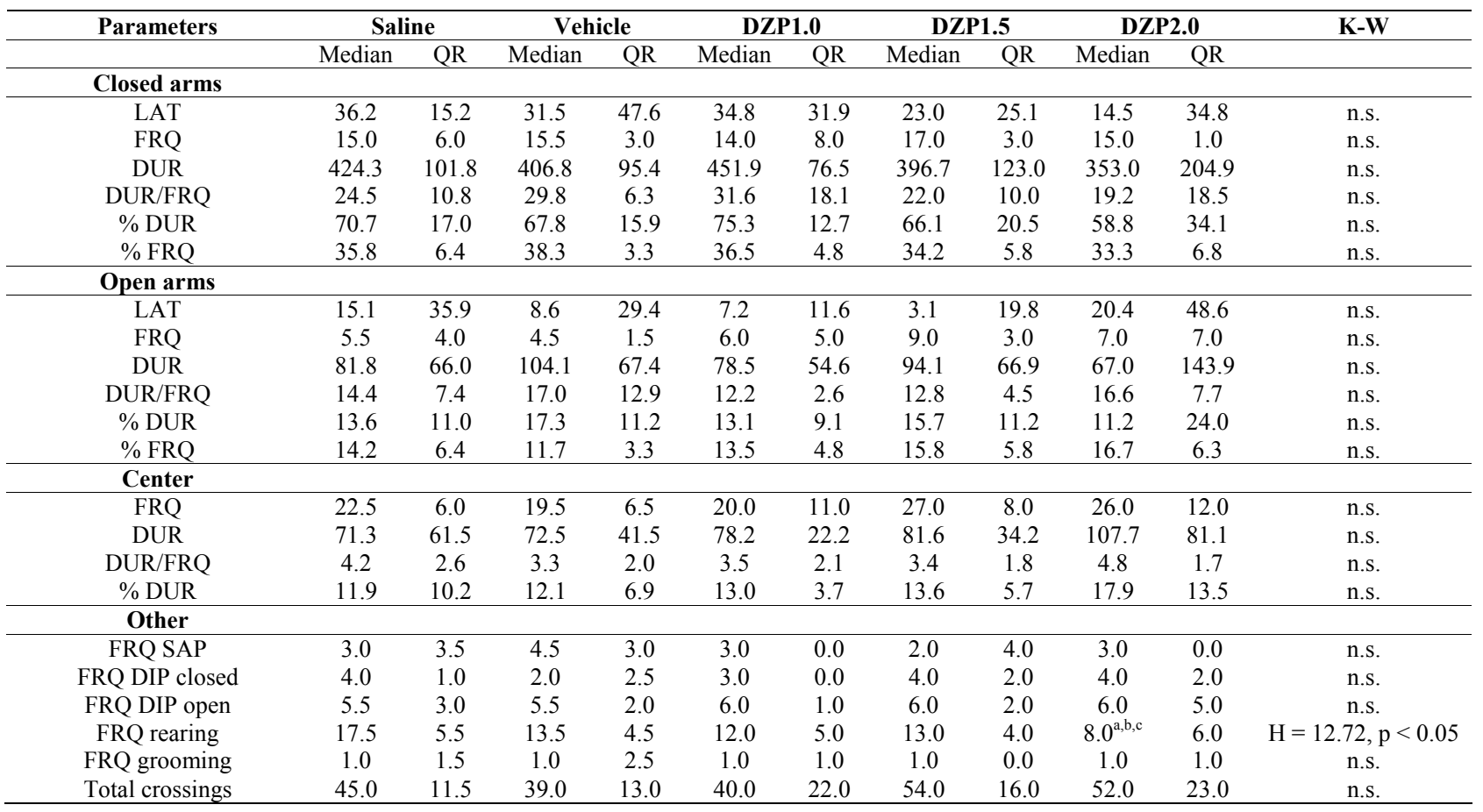

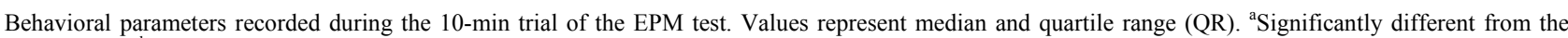
saline group; 'bignificantly different from the vehicle group; ${ }^{\mathrm{c}}$ Significantly different from the DZP1.0 group (p $\leq 0.05$; Mann-Whitney U-test). Abbreviations: DIP, head dip; DUR, duration (s); DUR/FRQ, duration per visit (s); FRQ, frequency; K-W, Kruskal-Wallis test; LAT, latency (s); SAP, stretched attend posture. 
dependent variables, the use of multivariate data analysis techniques enables extraction of information from the data not possible to obtain using traditional statistical approaches $[22,23]$. This also applies to data generated from the MCSF [e.g. 11,14,24]. In the present study, the usefulness of alternative ways of analyzing complex data sets generated from the MCSF was investigated by administering low doses of DZP prior to MCSF testing. The PLS-DA shows that the DZP1.5 group load separated from the other groups with a number of MCSF parameters important for this loading. In fact, the analysis illustrates that data although not providing a basis for conclusions on a conventional level of statistical significance still contribute to useful information (Table 1, Figure 2).

The trend analysis is based on a selection of functionally related MCSF parameters. A PCA of the parameters included in the trend analysis supports the selection made as the majority of parameters included in the different functional categories are correlated. A separation between risk-associated parameters performed on the bridge and in the central circle, respectively, can be found. This indicates that the animals experience an open, dimly illuminated area (central circle) differently compared to a brightly illuminated and elevated bridge construction (bridge). This is supported by experimental evidence of animals having higher risk-taking behavior on the bridge without differing in the behavior in the central circle $[14,20]$.

In the trend analysis in which the relative position of the animals within the entire population was used, a significant difference between the groups in the functional category general activity was revealed. Moreover, when performing a PCA on the sum rank scores from the trend analysis, the DZP1.5 rats were characterized by risktaking behavior in addition to general activity. Based on these findings, an additional trend analysis based on groupwise rankings (rather than all treatment groups) revealed significantly higher general activity and risk-taking behavior in DZP1.5 rats relative to vehicle rats. This finding supports the benefit of the trend analysis principally due to that the procedure takes into account varying behavioral strategies within the same functional context. In addition, the trend analysis adds explicit information that may be easier to penetrate than the multivariate data analysis from descriptive as well as inferential statistical point of view. The more detailed explanation of the use of the trend analysis can be found in a research article where it was used for behavioral characterization of dogs [16]. With regard to behavioral profiling using the MCSF, the usefulness of the trend analysis has been demonstrated in a number of studies [e.g. 14,24-26].

When comparing the statistically significant group differences obtained in the MCSF and EPM tests, respectively, we argue that the MCSF model provides a greater possibility to discover behavior responses caused by a particular stimulus situation. Some of the EPM components are to be found in the MCSF construction, (e.g. total activity versus total crossings, corridors versus closed arms). In spite of, or maybe due to, that the animal is provided more possibilities and choices to perform and subsequently express its mental condition, the MCSF test has the capacity to reveal effects of DZP that were not discovered using the EPM test.

Despite using doses that previously have been shown to increase open arm activity in the EPM [27,28] and activity in the central part of a novel open field [29], no group differences were detected in the EPM. This may be due to different animals used since both strain- [30] and supplier-dependent [24,31] differences have been observed. Moreover, in the previous studies [27-29], the animals were tested during the light period of the light/ dark cycle and no information about handling prior to testing is given. In contrast, both the multivariate data analysis and the trend analysis indicate an elevated risktaking behavior in the DZP1.5 rats relative to the vehicle rats, mainly related to the behavior in the central circle area, and an increase in general activity. The increased general activity cannot be explained by a specific motivation to explore the environment. The DPZ1.5 effect is rather suggested to be due to the fact that this amount of the drug causes a non-goal directed activity characterized by quick transfers from one zone to another.

Behavioral test batteries are commonly used for instance when phenotyping rats and mice. Problems with this approach include that the experience acquired in one test may have an effect in subsequent tests [32-34]. Moreover, experimenter handling, which increases with repeated testing, is a known source to variation [35]. In a battery combining the MCSF, open field and EPM tests, the MCSF test was found to be the most sensitive to previous experience [36]. The need for behavioral assays to be screened for usefulness on the basis of their replicability across laboratories has recently been emphasized [5]. The results obtained using different groups of selectively bred alcohol-preferring and alcohol non-preferring rats tested in the MCSF test has been possible to replicate across laboratories despite the fact that a smaller MCSF arena was used in one of the studies [14,15,20].

It is here concluded that the trend analysis together with multivariate data analysis procedures offers possibilities to extract information and illustrates effects obtained in the MCSF test. Diazepam in doses that have no apparent increase in open arm activity in the EPM was effective to alter the behavior in the MCSF test. The MCSF test and the use of multivariate data analysis and the proposed rank-order procedure, i.e. the trend analysis, may be useful alternatives to behavioral test batteries and traditionally used tests for the understanding of mecha- 
nisms underlying various mental states. We believe that the impact of an ethological reasoning and multivariate measures enabling behavioral profiling of animals will be a useful complementary methodology when phenotyping animals in behavioral neuroscience.

\section{Acknowledgements}

The authors are grateful for the skillful technical assistance of Ms. Marita Berg, and for financial support (E.R.) from the Alcohol Research Council of the Swedish Alcohol Retailing Monopoly (SRA 2011-0062; 2012-0047), the Swedish Society for Medical Research (SSMF), and the Facias, the Magnus Bergvall, the Åke Wiberg and the Fredrik \& Ingrid Thuring Foundations.

\section{REFERENCES}

[1] T. Nagel, "What Is It Like to Be a Bat?" The Philosophical Review, Vol. 83, No. 4, 1974, pp. 435-450. doi: $10.2307 / 2183914$

[2] A. Miklosi, "Dog Behaviour, Evolution, and Cognition," Oxford University Press, Oxford, 2007. doi:10.1093/acprof:oso/9780199295852.001.0001

[3] J. F. Cryan and A. Holmes, "Model Organisms: The Ascent of Mouse: Advances in Modelling Human Depression and Anxiety," Nature Reviews Drug Discovery, Vol. 4, 2005, pp. 775-790. doi:10.1038/nrd1825

[4] "Anonymous, Building a Better Mouse Test," Nature Methods, Vol. 8, 2011, p. 697. doi:10.1038/nmeth.1698

[5] E. Fonio, I. Golani and Y. Benjamini, "Measuring Behavior of Animal Models: Faults and Remedies," Nature Methods, Vol. 9, 2012, pp. 1167-1170. doi:10.1038/nmeth.2252

[6] E. J. Nestler and S. E. Hyman, "Animal Models of Neuropsychiatric Disorders," Nature Neuroscience, Vol. 13, 2010, pp. 1161-1169. doi:10.1038/nn.2647

[7] G. Winocur, M. Moscovitch, S. Fogel, R. S. Rosenbaum and M. Sekeres, "Preserved Spatial Memory after Hippocampal Lesions: Effects of Extensive Experience in a Complex Environment," Nature Neuroscience, Vol. 8, 2005, pp. 273-275. doi:10.1038/nn1401

[8] A. Ennaceur, S. Michalikova, R. van Rensburg and P. L. Chazot, "Are Benzodiazepines Really Anxiolytic? Evidence from a 3D Maze Spatial Navigation Task," Behavioural Brain Research, Vol. 188, No. 1, 2008, pp. 136153. doi:10.1016/j.bbr.2007.10.026

[9] A. Ramos, "Animal Models of Anxiety: Do I Need Multiple Tests?" Trends in Pharmacological Sciences, Vol. 29, No. 10, 2008, pp. 493-498. doi:10.1016/j.tips.2008.07.005

[10] R. J. Blanchard, E. B. Yudko, R. J. Rodgers and D. C. Blanchard, "Defense System Psychopharmacology: An Ethological Approach to the Pharmacology of Fear and Anxiety," Behavioural Brain Research, Vol. 58, No. 1-2, 1993, pp. 155-165. doi:10.1016/0166-4328(93)90100-5

[11] B. J. Meyerson, H. Augustsson, M. Berg and E. Roman,
"The Concentric Square Field: A Multivariate Test Arena for Analysis of Explorative Strategies," Behavioural Brain Research, Vol. 168, No. 1, 2006, pp. 100-113. doi:10.1016/j.bbr.2005.10.020

[12] D. C. Blanchard, G. Griebel and R. J. Blanchard, "The Mouse Defense Test Battery: Pharmacological and Behavioral Assays for Anxiety and Panic," European Journal of Pharmacology, Vol. 463, No. 1-3, 2003, pp. $97-$ 116. doi:10.1016/S0014-2999(03)01276-7

[13] R. J. Blanchard and D. C. Blanchard, "Antipredator Defensive Behaviors in a Visible Burrow System," Journal of Comparative Psychology, Vol. 103, No. 1, 1989, pp. 70-82. doi:10.1037/0735-7036.103.1.70

[14] E. Roman, R. B. Stewart, M. L. Bertholomey, M. L. Jensen, G. Colombo, P. Hyytiä, N. E. Badia-Elder, N. J. Grahame, T. K. Li and L. Lumeng, "Behavioral Profiling of Multiple Pairs of Rats Selectively Bred for High and Low Alcohol Intake Using the MCSF Test," Addiction Biology, Vol. 17, No. 1, 2012, pp. 33-46. doi:10.1111/j.1369-1600.2011.00327.x

[15] E. Roman and G. Colombo, "Lower Risk Taking and Exploratory Behavior in Alcohol-Preferring sP Rats than in Alcohol Nonpreferring sNP Rats in the Multivariate Concentric Square Field ${ }^{\mathrm{TM}}$ (MCSF) Test," Behavioural Brain Research, Vol. 205, No. 1, 2009, pp. 249-258. doi:10.1016/j.bbr.2009.08.020

[16] H. Åkerberg, E. Wilsson, M. Sallander, Å. Hedhammar, A. L. Lagerstedt, D. Larhammar and B. Meyerson, "Test for Personality Characteristics in Dogs Used in Research," Journal of Veterinary Behavior: Clinical Applications and Research, Vol. 7, No. 6, 2012, pp. 327-338. doi:10.1016/j.jveb.2012.01.007

[17] K. Uekama, F. Hirayama and T. Irie, "Cyclodextrin Drug Carrier Systems," Chemical Reviews, Vol. 98, No. 5, 1998, pp. 2045-2076. doi:10.1021/cr970025p

[18] T. L. Yaksh, J. D. Jang, Y. Nishiuchi, K. P. Braun, S. G. Ro and M. Goodman, "The Utility of 2-HydroxypropylBeta-Cyclodextrin as a Vehicle for the Intracerebral and Intrathecal Administration of Drugs," Life Sciences, Vol. 48, No. 7, 1991, pp. 623-633. doi:10.1016/0024-3205(91)90537-L

[19] L. Eriksson, E. Johansson, N. Kettaneh-Wold, J. Trygg, C. Wikström and S. Wold, "Multi- and Megavariate Data Analysis. Part I: Basic Principles and Applications," 2nd Revised and Enlarged Edition, Umetrics AB, Umeå, 2006.

[20] E. Roman, B. J. Meyerson, P. Hyytiä and I. Nylander, "The Multivariate Concentric Square Field Test Reveals Different Behavioural Profiles in Male AA and ANA Rats with Regard to Risk Taking and Environmental Reactivity," Behavioural Brain Research, Vol. 183, No. 2, 2007, pp. 195-205. doi:10.1016/j.bbr.2007.06.009

[21] O. Karlsson, E. Roman and E. B. Brittebo, "Long-Term Cognitive Impairments in Adult Rats Treated Neonatally with \{beta\}-N-Methylamino-L-Alanine (BMAA)," Toxicological Sciences, Vol. 112, No. 1, 2009, pp. 185-195. doi:10.1093/toxsci/kfp196

[22] S. J. Dahlbom, D. Lagman, K. Lundstedt-Enkel, L. F. Sundstrom and S. Winberg, "Boldness Predicts Social 
Status in Zebrafish (Danio rerio)," PLoS One, Vol. 6, 2011, Article ID: e23565. doi:10.1371/journal.pone.0023565

[23] K. Lundstedt-Enkel, R. Bjerselius, L. Asplund, K. Nylund, Y. Liu and M. Sodervall, "Modeling Relationships between Baltic Sea Herring (Clupea harengus) Biology and Contaminant Concentrations Using Multivariate Data Analysis," Environmental Science \& Technology, Vol. 44, No. 23, 2010, pp. 9018-9023. doi:10.1021/es102448b

[24] S. Palm, Å. Hävermark, B. J. Meyerson, I. Nylander and E. Roman, "When Is a Wistar a Wistar? Behavioral Profiling of Outbred Wistar Rats from Five Different Suppliers Using the MCSF Test," Applied Animal Behaviour Science, Vol. 135, No. 1, 2011, pp. 128-137. doi:10.1016/j.applanim.2011.08.010

[25] L. Daoura, M. Hjalmarsson, S. Oreland, I. Nylander and E. Roman, "Postpartum Behavioral Profiles in Wistar Rats Following Maternal Separation-Altered Exploration and Risk-Assessment Behavior in MS15 Dams," Frontiers in Behavioral Neuroscience, Vol. 4, 2010, p. 37.

[26] S. Ekmark-Lewen, A. Lewen, B. J. Meyerson and L. Hillered, "The Multivariate Concentric Square Field Test Reveals Behavioral Profiles of Risk Taking, Exploration, and Cognitive Impairment in Mice Subjected to Traumatic Brain Injury," Journal of Neurotrauma, Vol. 27, No. 9, 2010, pp. 1643-1655. doi:10.1089/neu.2009.0953

[27] G. Griebel, G. Perrault and D. J. Sanger, "Characterization of the Behavioral Profile of the Non-Peptide CRF Receptor Antagonist CP-154,526 in Anxiety Models in Rodents. Comparison with Diazepam and Buspirone," Psychopharmacology (Berl), Vol. 138, No. 1, 1998, pp. 55-66. doi:10.1007/s002130050645

[28] M. A. Wilson, P. R. Burghardt, K. A. Ford, M. B. Wilkinson and S. D. Primeaux, "Anxiolytic Effects of Diazepam and Ethanol in Two Behavioral Models: Comparison of Males and Females," Pharmacology Biochemistry and Behavior, Vol. 78, No. 3, 2004, pp. 445-458. doi:10.1016/j.pbb.2004.04.017

[29] R. Stefanski, W. Palejko, W. Kostowski and A. Plaznik, "The Comparison of Benzodiazepine Derivatives and Se- rotonergic Agonists and Antagonists in Two Animal Models of Anxiety," Neuropharmacology, Vol. 31, No. 12, 1992, pp. 1251-1258. doi:10.1016/0028-3908(92)90053-R

[30] A. O. Mechan, P. M. Moran, M. Elliott, A. J. Young, M. H. Joseph and R. Green, "A Comparison between Dark Agouti and Sprague-Dawley Rats in Their Behaviour on the Elevated Plus-Maze, Open-Field Apparatus and Activity Meters, and Their Response to Diazepam," Psychopharmacology (Berl), Vol. 159, No. 2, 2002, pp. 188195. doi:10.1007/s002130100902

[31] A. A. Goepfrich, C. Gluch, C. M. Friemel and M. Schneider, "Behavioral Differences in Three Wistar Han Rat Lines for Emotional Reactivity, Cognitive Processing and Ethanol Intake," Physiology \& Behavior, Vol. 110-111, 2013, pp. 102-108. doi:10.1016/j.physbeh.2012.12.019

[32] R. Paylor, C. M. Spencer, L. A. Yuva-Paylor and S. Pieke-Dahl, "The Use of Behavioral Test Batteries, II: Effect of Test Interval," Physiology \& Behavior, Vol. 87, No. 1, 2006, pp. 95-102.

doi:10.1016/j.physbeh.2005.09.002

[33] V. Voikar, E. Vasar and H. Rauvala, "Behavioral Alterations Induced by Repeated Testing in C57BL/6J and 129S2/Sv Mice: Implications for Phenotyping Screens," Genes, Brain and Behavior, Vol. 3, No. 1, 2004, pp. 27 38. doi:10.1037/0735-7044.121.5.1113

[34] S. J. Ballaz, H. Akil and S. J. Watson, "Previous Experience Affects Subsequent Anxiety-Like Responses in Rats Bred for Novelty Seeking," Behavioral Neuroscience, Vol. 121, No. 5, 2007, pp. 1113-1118. doi:10.1037/0735-7044.121.5.1113

[35] J. C. Crabbe, D. Wahlsten and B. C. Dudek, "Genetics of Mouse Behavior: Interactions with Laboratory Environment," Science, Vol. 284, No. 5420, 1999, pp. 1670-1672. doi:10.1126/science.284.5420.1670

[36] H. Augustsson, "Ethoexperimental Studies of Behaviour in Wild and Laboratory Mice. Risk Assessment, Emotional Reactivity and Animal Welfare," Acta Universitatis Agriculturae Sueciae Veterinaria, Vol. 174, 2004, pp. 762 . 